\title{
A Comparative Study of Cytoplasmic Inclusions (Volutin Granules) in Different Species of Trypanosomes
}

\author{
BY W. E. ORMEROD \\ Department of Parasitology, London School of Hygiene and \\ Tropical Medicine, London, W.C. 1
}

SUMMARY: The literature of 'volutin' granules is reviewed in an attempt to clarify the meaning of the term in respect to trypanosomes. Fifteen species of trypanosomes have been examined by phase-contrast microscopy and the morphology and natural history of their cytoplasmic inclusions described. It is suggested that the formation of inclusions in trypanosomes circulating in the blood of mammals represents a constant phenomenon which is closely related in time to the immune reaction of the host; other evidence suggests that this relationship is not fortuitous. In addition, the formation of inclusions in Trypanosoma rhodesiense and T. levisi appears to be related to polymorphism, notwithstanding the wide differences in the manner and time in which polymorphism (and associated cytoplasmic inclusions) occur within their cycles in the vertebrate host.

This paper describes the morphology and discusses the significance of inclusions which occur in the cytoplasm of trypanosomes circulating in the blood of vertebrates. My attention was first drawn to these inclusions by their presence in many laboratory strains of trypanosomes, by their complete absence from others, and by the resemblance of these inclusions to those produced by Antrycide and other drugs in strains in which these inclusions do not normally occur. Because of this resemblance I suggested (Ormerod, 1951) that these inclusions which occur naturally might be produced-in the same way as by drugs-by basic or acidic substances, in this instance derived from the host, circulating in the blood and able to be absorbed by the trypanosome and to disrupt the ribonucleoprotein in the cytoplasm into its constituent protein and ribonucleic acid. I began this study of the morphology of these inclusions to obtain evidence for or against this hypothesis. Similar inclusions occur in the leptomonad and crithidial forms of trypanosomes, both in culture and in the gut of invertebrates; they also occur in flagellates and other protozoa generally that are not adapted to vertebrate blood. These will be considered only in relation to the main phenomenon, namely, the presence or absence of inclusions in blood trypanosomes; it is hoped to consider them in more detail in a later paper.

\section{Historical survey}

Volutin. The term 'Volutans granules' was coined by Grimme (1902) to denote granules which occur in various plant, fungal and bacterial cells with staining properties resembling those of Spirillum volutans; Meyer (1904) subsequently altered the term to 'volutin' because he realized that it represented a chemical substance or reaction type that was common to most, if not all, 
forms of life. He devised a series of tests based on the stability of the granules to water, acids and alkalis, their staining properties with methylene blue and its retention under the action of solvents. Meyer's insight into the nature of volutin was shown by his comparison of volutin granules present in yeast with the substance that had been isolated from yeast by Kossel (1882) and called 'Hefe-nukleinsäure'; Meyer showed that there was a close similarity between the reactions of these substances and believed that they were in fact the same. Since that date the chemistry of nucleic acid has developed enormously and Kossel's yeast nucleinic acid, now called 'ribonucleic acid' is recognized as being present in the nucleus and cytoplasm of all living cells; the nature of the granules has, however, been obscured, partly because of the use of the term 'volutin' that has satisfied workers who, having performed Meyer's tests, were content with this identification and failed to inquire further about their nature, and because of controversy (Guilliermond, 1910) about whether these granules should be called 'volutin' or 'metachromatic'. The term 'metachromatic granules' certainly seems to have been the first used to describe these structures (Babes, 1895) but has the disadvantage of making the phenomenon of metachromasia the main feature of identification. This is unsatisfactory because: (a) as a chemical phenomenon it is imperfectly understood, being related more to the concentration of the dye than to the nature of the granule (Michaelis, 1944); (b) it is known to give positive results with substances of a totally different nature such as heparin, dextran sulphate (Walton, 1952), metaphosphate polymers (Dämle \& Krishnan, 1954) and mucopolysaccharides (Lison, 1935); (c) as will be shown later in this paper, inclusions apparently of the same nature sometimes do not stain at all.

The phenomenon of metachromasia has, however, directed attention to a constituent of the volutin granules in yeast, and it has been demonstrated (Wiame, 1947) that a substance can be extracted from yeast and that its presence or absence determines the metachromasia of the volutin granules. This substance has been identified (Ebel, 1952) as 'Graham's salt', an inorganic long-chain metaphosphate polymer having the property of combining with proteins and with metallic ions. It is uncertain, however, whether these findings are of significance to the study of cytoplasmic inclusions in trypanosomes. In protozoological literature the interest in volutin stems entirely from Meyer's work, but after the description of volutin granules in various protozoa (in Coccidia, Kunze, 1907; in trypanosomes, Swellengrebel, 1908; in Sarcosporidia, Erdmann, 1910; in Haemogregarines, Reichenow, 1910) protozoologists appear to have lost interest in this barren concept.

Swellengrebel (1908) first gave an adequate description of volutin granules in trypanosomes and identified their substance by Meyer's tests. His description is sometimes difficult to follow since it involves the extrusion of these granules from the nucleus along an 'achromatic axial filament'. It is evident from his figures that he was dealing with inclusions similar to those being considered here, and I believe that his description represents the observation (which will be referred to in the section on Results) that the inclusions in Trypanosoma rhodesiense are often to be found strung like beads 
in one or two chains in the long axis of the trypanosome anterior to the nucleus. These granules do not always take up the stain, and under these circumstances give the appearance of an achromatic filament. Similar observations were also made by Salvin-Moore \& Breinl (1908). They noted granules which stained with a methylene-blue + safranine stain and which were present in all trypanosomes at some times, absent at others, and had no connexion with the nucleus.

A single granule was described in the mature blood forms of Trypanosoma lewisi by Wenyon (1926); this granule occurred near the nucleus and stained red with Giemsa. A similar granule was described by Wolcott (1952) as taking part in nuclear division in the early forms of $T$. lewisi. I have seen instances of this granule; it can often be seen in occasional trypanosomes in a heavy infection of $T$. lewisi, but I am unable to say whether it is in any way related to the inclusions described in the present paper. Another granule was described by Minchin (1909), in osmic acid-fixed specimens of $T$. lewisi; this finding will be referred to in the section on Results.

The most important study hitherto of volutin granules in trypanosomes was made by van den Berghe (1942). He returned to the view of Meyer (1904) which had again been made acceptable by the work of Casperson \& Brand (1941) who studied the ultraviolet absorption of yeast volutin and demonstrated its probable identity with ribonucleic acid. Van den Berghe used the technique of Brachet (1941) of identification by specific digestion of the granules with pancreatic ribonuclease; although his results must be considered with caution both because of difficulties of interpretation (Ormerod, 1951) and because the enzyme available at that period was contaminated with protease, there is little doubt of the general validity of his conclusions that volutin granules in trypanosomes consist largely of ribonucleic acid, that they are not disintegrated products from the nucleus and that they have no direct connexion with the nucleus or with nuclear chromatin.

In cold-blooded vertebrate hosts cytoplasmic granules appear to be a frequent feature of trypanosomes and have been described in Trypanosoma diemyctyli in the American triton by Nigrelli (1929) and by Barrow (1954). Barrow studied the granules by histochemical methods and realized their acid nature but, adopting the interpretation of Lison (1935), he took their metachromatic staining to indicate the sulphate groups of a mucopolysaccharide. Gerzeli (1955), studying $T$. granulosum in the eel (Anguilla vulgaris), T. remaki in the pike (Essox lucius) and T. wenyoni in the bullhead (Gobius fluvialus), used the more specific 'periodic acid-Schiff' reaction (Hotchkiss, 1948), and was unable to detect polysaccharide; he was, however, able to identify ribonucleic acid in the granules of these trypanosomes and in the granules present in laboratory strains of $T$. brucei in mice and $T$. gambiense in guineapigs.

In Toxoplasma gondii granules occur which have been observed under phase contrast (Lelong \& Desmonts, 1951) and by the electron microscope (Bringmann \& Holz, 1953).

Vital staining with granule formation occurs in Toxoplasma with a solution of methylene blue (Sabin \& Feldman, 1948), but after treatment with an 
immune serum approximately nine-tenths of the organisms fail to take up the stain. Lelong \& Desmonts were able to show that this was because granule formation had already taken place under the action of the serum and had inhibited subsequent staining, the change being visible under phase contrast within a minute of applying the serum; and Bringmann \& Holz identified the granules as being composed largely of ribonucleic acid, but regarded their formation as unspecific since they were produced also by antibiotics (unspecified).

As stated above, the first intention of the present work was to explore the hypothesis that the granules in the cytoplasm of untreated trypanosomes might be produced by some circulating substance derived from the host and absorbed into the trypanosome. The second purpose of this work was to establish whether these inclusions were of practical significance or not, that is to say, whether they occurred in naturally-transmitted infections and in infections occurring in the field, particularly those of medical and economic importance. It would have been of interest but of little practical value had they been found to be laboratory artifacts. For this purpose the natural history of the granules, that is to say, the morphology, the times of appearance and disappearance, their relationship to changes in the trypanosome, to the vertebrate host, and to the means of transmission (by insect vector or by syringe) has been studied. The study has been made in as many species of trypanosomes as were available, in the belief that this phenomenon in circulating trypanosomes might be in association with the adaptation of the flagellate to a parasitic existence in vertebrate blood, and that it might be expected to vary at different phases of evolution throughout the genus Trypanosoma.

\section{METHODS}

As far as possible natural infections have been used in this study. It has been known since the work of Bruce et al. (1915) that strains of African pathogenic trypanosomes can change considerably in their morphology and behaviour when isolated in the laboratory. Where natural infections or infections transmitted in the laboratory by arthropod vector could not be studied, strains of recent isolation were used. It is from these three types of strain that the main conclusions of the work are drawn, while strains which had been passaged artificially in the laboratory for long periods were used only for comparison to show the range of adaptation to which the different species were capable in respect of formation of inclusions.

Observations were made with the phase-contrast microscope (Cooke, Troughton \& Sims; $\times 95$ oil-immersion objective). For this purpose a small drop of blood was placed on a coverslip which was applied to a slide faced with a gel of $1 \%(\mathrm{w} / \mathrm{v})$ agar in physiological saline. The blood spreads by capillary action between the agar and coverslip to form a single layer of cells, the corpuscles being arranged edge to edge to form a 'phalanx'. Trypanosomes are best observed either at the edge of the phalanx, or if the coverslip is moved gently from side to side, in gaps which appear in the phalanx; trypanosomes 
moving in the unbroken phalanx cannot accurately be observed since the degree of contrast of inclusions against cytoplasm is diminished by the proximity of the more refractile red blood corpuscles. By this method, for which I am indebted to Mr J. Smiles, it is possible to observe living trypanosomes under oil immersion as clearly as if stained on a dry smear, and with the cytoplasmic inclusions displayed with greater clarity than by any other method. Photography is, however, rarely possible because the movement is still rapid, still (to some extent) three-dimensional and because of the low transmission of light by the phase-contrast system. All illustrations used in this paper are therefore free-hand drawings.

Observations were also made on dry fixed preparations stained with 'Revector' Giemsa stain. In spite of the convenience of obtaining permanent preparations it was found in practice that this was an unreliable method for detecting the presence of inclusions since (as will be shown later) several species of trypanosomes appeared capable of undergoing a change whereby the inclusions were no longer able to take up the stain.

Histochemical methods were used at first in an attempt to study the chemical nature of the granules; some of these methods have been described and their disadvantages given in relation to this type of work (Ormerod, 1951). In this former paper the main reliance for the identification of nucleic acid was the tetrazonium reaction of Mitchell (1942) and Danielli (1947). Barnard \& Danielli (1956) have since shown that this reaction is not specific for purines and pyrimidines as was then supposed, but reacts specifically with histidine; although it is usually positive in deposits of nucleic acids, it is in fact an indication of the presence of protein and not of nucleic acid. For this reason, because of the unreliability of other techniques available, and because so many previous workers have been led to wrong conclusions by the use of histochemical technique, I felt that it was necessary to confine these observations to morphology and reserve for a later date a more precise study of the chemical nature of granules isolated from suitable species of trypanosomes.

\section{RESULTS}

The species studied are arranged in a classification adapted from Hoare (1957) and from Wenyon (1926).

\section{Group I}

(1) Trypanosoma lewisi (Kent, 1880). Three strains of $T$. lewisi were examined.

Strain 1, the 'Winches' strain, was isolated $3 \frac{1}{2}$ years previously from a wild Rattus norvegicus at Winches Farm, St Albans, Hertfordshire. The strain was passaged by syringe in laboratory rats and produced high blood infection which would last in some rats for long periods (maximum 12 months) after which it would vanish from the blood. The monomorphic adult form, Pl. 1, fig. 1 , that is to say, the form circulating after 15 days of passage-contained a single granule in the region of the kinetoplast (two inclusions were sometimes present in these forms). At the beginning of the infection from the 6th to 
12th day when the infection was polymorphic, immature forms which were broader and thicker than the adults were present; these contained multiple inclusions (Pl. 1, fig. 2) which were faint and could not be counted with ease as they were grouped together in the region of the kinetoplast. They were most obvious at about the 10th day after which the number of trypanosomes so affected declined until about the 15th day, when all trypanosomes remaining in the circulation were of the adult form. The decline in the granular trypanosomes coincided with the overall decline in total numbers.

In dry smears stained with Giemsa these inclusions did not stain and could only sometimes be seen as gaps in the cytoplasm. In trypanosomes with multiple inclusions it was easy, by comparing stained and living organisms, to show that the inclusions were distinct from the kinetoplast. This was not so easy in the adult trypanosome where one inclusion only was present. I believe, however, that they are distinct and that the inclusion usually lies posterior to the kinetoplast, as did the osmiophilic granule noted by Minchin (1909).

Occasional single inclusions (c. 1/100 trypanosomes) were seen in dry fixed films stained with Giemsa; these stained lightly and were eosinophilic, did not appear under phase contrast, and may correspond to those referred to by Wenyon (1926) and by Wolcott (1952). Passage through the flea Xenopsylla cheopis did not change the behaviour or appearance of this strain.

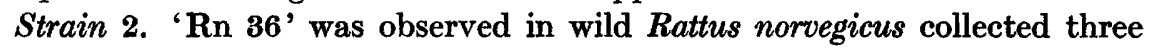
and a half years later and within 200 yards of the site of collection of the 'Winches' strain. In the original rat approximately one in ten trypanosomes contained two to three inclusions and there was slight polymorphism. Passage was obtained in laboratory rats. At the third passage 75 days after isolation, the strain was examined (parallel observations were made with Strain 1 at the same time); the appearances in the two strains were identical but maximal inclusion formation occurred 4 days later in strain 2. Disappearance of inclusions and assumption of the adult form was similarly delayed.

Nineteen months later strains 1 and 2 were indistinguishable, the time of maximal inclusion formation varied from 5 to 15 days depending on the age and in particular on the strain of rat used for passage; there was no variation, however, in the appearance of the trypanosome, or of the inclusions.

Strain 3 was observed in a wild Rattus rattus trapped on a ship that had arrived from Jamaica. The rat had been dead for some hours but the trypanosomes were motile and of the adult type, resembling those in Pl. 1, fig. 1. Passage into laboratory rats failed.

(2) Trypanosoma duttoni Thiroux 1900. A single strain of this organism was examined in a wild house-mouse Mus musculus. Five individuals were seen under phase contrast, four were adult forms, and contained a single inclusion in the region of the kinetoplast. One was broader than the others (presumably an immature form) and contained inclusions (number not noted) between the region of the kinetoplast and the nucleus. Broad forms were present in the stained film and these contained inclusions that stained violet. Passage into laboratory mice failed. 
(3) Trypanosoma grosi Laveran \& Pettit, 1909. Two strains of this trypanosome (Pl. 1, fig. 3) were examined in their original host, the long-tailed field mouse Apodemus sylvaticus trapped in the woods and hedgerows at Winches Farm. They were passaged into animals of the same species which, having been trapped and kept in captivity for several weeks without showing infection, were presumed clean.

Table 1. Trypanosoma grosi infection at first syringe passage into wild caught long-tailed field mice (Apodemus sylvaticus). Table showing the relative numbers of inclusions seen under phase-contrast and in Giemsa-stained preparations

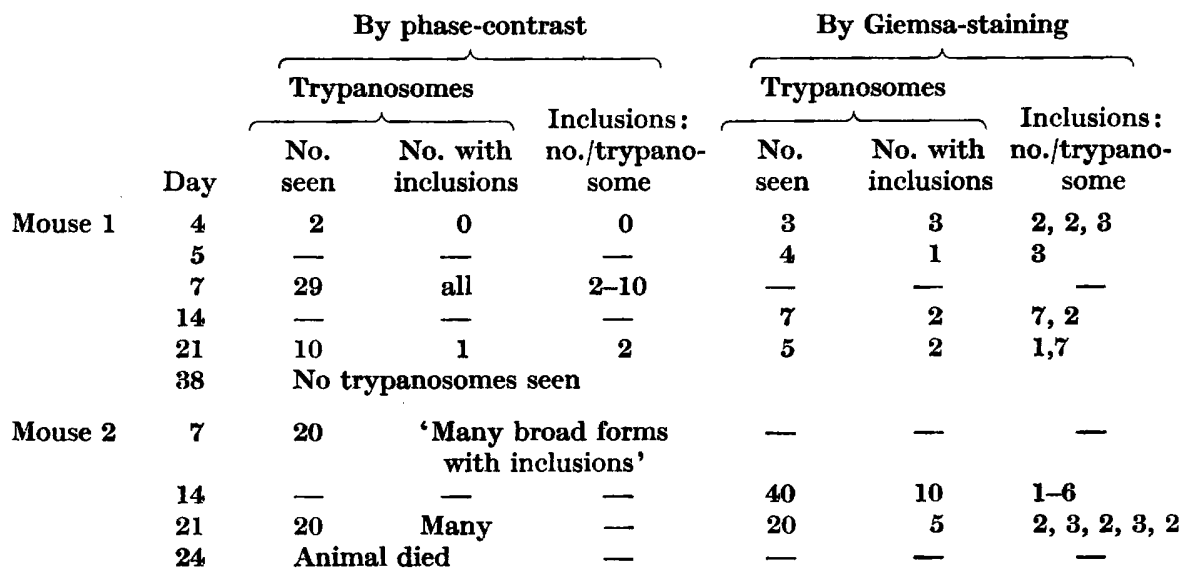

Strain 1. On capture twenty-one trypanosomes were seen under phase contrast; one was broad and contained five inclusions. In a dry film on the same day stained with Giemsa, out of forty organisms, seven contained from two to five inclusions. The strain was passaged by injection into two Apodemus sylvaticus and the results of this infection are shown in Table 1 . The inclusions were in all cases near the region of the kinetoplast but not so closely confined to this region as in Trypanosoma lewisi. They were chiefly in the broad forms and in these broad forms were present in their clearest form and greatest number. Although they were similar to those seen with phase contrast in $T$. lewisi they were slightly more refractile and more easily seen, in addition they were frequently (perhaps always) stainable with Giemsa. The observations in Table 1 show in addition that inclusions (and the broad forms in which they occur) were present-(in contrast to $T$. lewisi) throughout much of the duration of the infection.

Strain 2 showed an infection with narrow forms only, without inclusions; this strain was not passaged.

(4) Trypanosoma evotamys Hadwen, 1912. This trypanosome was seen on three occasions in the bank vole Clethrionomys (Evotamys) glariolus; in each instance only the typical lewisi-like adult was observed and passage was not obtained. 
(5) Trypanosoma acomys Wenyon, 1909. A spiny mouse Acomys sp. was kindly sent by $\operatorname{Dr}$ A. Zuckerman from Israel. Faint inclusions with little refractile power were present in most forms, but little idea of the significance of these inclusions was obtained before the infection died out.

(6) Trypanosoma cruzi Chagas, 1909. Strain 1. 'Sonya' strain (Garnham, 1956) was studied in newly weaned rats and in mice. These were infected with the dejecta of laboratory-bred Triatoma infestans which had been fed on a human case of Chagas' disease. The appearances of the organism (Pl. 1, fig. 4) were constant from the time the animal showed the infection (about 12 days) to its death. The inclusions were large, constant in size, and distributed on either side of the nucleus; too closely packed to be counted in a motile organism, they did not stain with Giemsa.

Strain 2. The ' $\mathrm{Y}$ ' strain had been isolated in 1950 and passaged in rats and mice by syringe and cyclically by $T$. infestans (Rego \& Garnham, 1956). The appearance was identical with strain 1.

Strain 3. 738 LM strain (Liverpool School of Tropical Medicine). Passaged by syringe in mice for a number of years; the appearances were identical with those of strains 1 and 2.

(7) Trypanosoma nabiasi Railliet, 1895. This was not seen under phase contrast. Slides stained with Giemsa kindly lent by Dr M. Singh Grewal showed basophilic inclusions in the broad immature forms similar to those described above for $T$. grosi.

(8) Trypanosoma avium Danilewsky, 1885. I was able to examine this trypanosome from the blood of a jackdaw (Corvus monedula spermologus) infected by eating numerous louse flies (Ornithomyia avicularis) which had been obtained from rooks (C. frugilegus frugilegus) (Baker, 1955). Three specimens of this very occult organism were seen under phase contrast; none contained inclusions. There was no evidence of inclusions in stained preparations.

\section{Group II}

(9) Trypanosoma vivax Ziemann, 1905. Strain 1. 'Vom' strain : Desowitz \& Watson (1953). This strain was adapted to syringe passage in rats which it killed within 4 days, such was the virulence of its infection. The cytoplasm was clear throughout and in repeated examination no inclusion was ever seen.

Strain 2. Examinations were made in the field at Kenaba, Gambia. Two zebu bulls from a tsetse-free area north of Kaolack, Senegal, were shipped over the Gambia River (Barra to Bathurst). On day 1 the blood contained no trypanosomes, neither did the blood of the other forty-eight cattle in the same herd. The blood remained negative until day 6 when one animal showed a blood infection with Treponema theileri (this is probably of no significance but has been recorded because of possible immune relationships between the two types of infection (Thompson \& DeMuro, 1932). On day 7 the bulls were carried by lorry to Tankolar (a village on the south bank of the Gambia River, and the north shore of the Bintang promontory) which was heavily infested with Glossina morsitans. On the 14th day both bulls showed an infection with Trypanosoma vivax which remained constant, at the rate of about 1 trypano- 
some/50 microscopic fields ( $\times 600$ magnification), until the death of the animals on days 19 and 27 , respectively. It is uncertain when the infective tsetse bites occurred, but the bulls were twice exposed to tsetse $(a)$ on the 4- to 5-day journey from Kaolack, i.e. in the 7 days preceding day 1 , giving an incubation period of 14-21 days, or $(b)$ at Tankolar from day 7 onwards, giving a maximum incubation period of 7 days. The longer period is the more likely, both on general grounds and from the low-grade infection which followed. The appearance of the trypanosomes was constant in both animals throughout the infection: all trypanosomes contained inclusions which lay on either side of the region of the nucleus. There were also inclusions in the region of the kinetoplast but not invariably in this position; from one to five inclusions/ trypanosome (seldom more than three) were seen. The inclusions did not stain with Giemsa.

\section{Group III (Congolense group)}

(10) Trypanosoma congolense Broden, 1904. I have examined no strain of $T$. congolense that has been transmitted other than by syringe. Numerous laboratory strains which I have examined show wide variation. Acute infections are sometimes without inclusions, more chronic infections show fine granules; inclusions or sometimes refractile bodies the size of (but in the wrong position for) the nucleus. I have not yet seen stained cytoplasmic inclusions in this species but $I$ am aware that others have.

(11) Trypanosoma simiae Bruce et al. 1911. I examined one strain of this trypanosome at Vom. It had been isolated from a domestic pig which had been bitten by wild Glossina morsitans. The strain had been passaged twice by syringe in rabbits and finally by fly into a pig-which developed a heavy infection within 6 days. The cytoplasm of the trypanosomes was clear and without inclusions. The pig died on the following day.

\section{Group IV (Brucei group)}

(12) Trypanosoma brucei Plimmer \& Bradford, 1899. I examined only syringe-passaged strains of this species. All strains had become more or less monomorphic on passage, with irregular and scanty inclusions. Acute strains killing the animal in 3 or 4 days were free from inclusions.

(13) Trypanosoma rhodesiense Stephens \& Fantham, 1910. Strain 1. The 'Maun' strain had been isolated from man in Bechuanaland by Dr Hansford. The fly involved in this area is Glossina morsitans. A guinea-pig was inoculated from the original patient and I examined the blood 10 days later. An infection of the order of 2 trypanosomes/field ( $\times 600$ magnification) was established. The infection consisted of approximately equal numbers of long thin and of short stumpy forms. The long thin forms had clear highly refractile cytoplasm, and the short stumpy forms contained inclusions; forms intermediate in length were also present and these were intermediate also in the number and size of the inclusions that they contained. As the infection declined, the short stumpy forms became relatively more numerous and the granules that they contained became more numerous and larger, until on day 17 of the infection 
the few remaining trypanosomes consisted of short, stumpy, posterior nuclear forms with many large granules, some as large as nuclei but spherical and more highly refractile. On day 18 the infection was absent, but slowly re-established itself to $c .10$ trypanosomes $/ \times 600$ field at day 40 ; it remained at about this value with little fluctuation in the numbers of long and short forms (the granules remaining confined to the short forms) until the death of the animal on day 92.

The infection in rats was similar; since larger numbers of trypanosomes circulated, it was easier to study. Pl. 2, fig. 5 shows organisms of the Maun strain, 11 months after isolation, differing in no material way either in appearance or behaviour from when it was first isolated. All inclusions are large

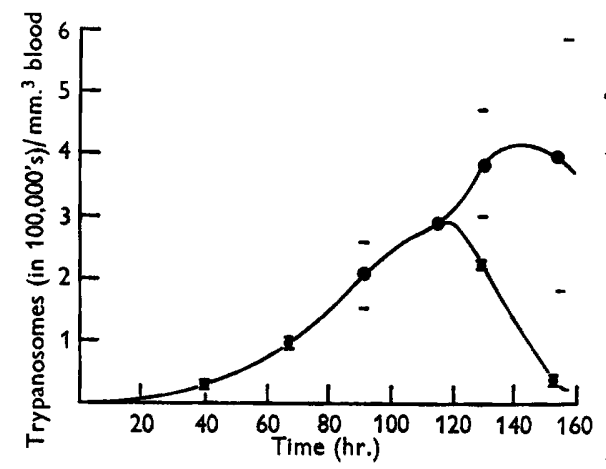

Fig. 1

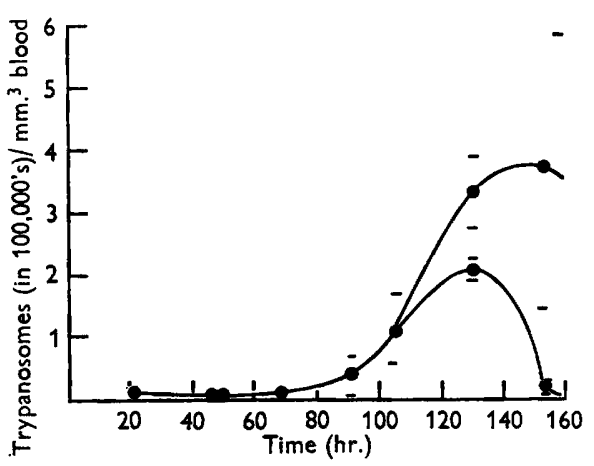

Fig. 2

Fig. 1. Trypanosoma rhodesiense. 'Maun' strain. Graph showing the mean total number of trypanosomes (with standard deviation) plotted against time. The upper limb of the bifurcation shows the course of the infection in two rats (out of the total six) in which the crisis was delayed.

Fig. 2. Trypanosoma rhodesiense. 'Maun' strain. To be read in conjunction with Fig. 1. Graph showing the mean number of trypanosomes containing inclusions. Until $60 \mathrm{hr}$. the trypanosomes were almost without inclusions, the proportion then increased until the crisis, after which all trypanosomes in the circulation contained inclusions.

and easily counted; absent in long, thin forms, present but scanty in intermediate forms, and very well marked in short stumpy forms, in particular posterior nuclear forms. Fig. 1 shows the growth of the infection up to the time of crisis; in two out of the six rats used in these observations, the crisis was delayed and the course of their crisis is shown in the upper bifurcation of the curve. Figure 2 shows the increase after $60 \mathrm{hr}$. of trypanosomes containing inclusions. Figure 3 shows the degree to which trypanosomes circulating in the blood were affected by inclusions. Up to $40 \mathrm{hr}$. a relatively large number of trypanosomes contained inclusions and these were most probably trypanosomes which had contained inclusions before injection; between 40 and $60 \mathrm{hr}$. trypanosomes containing inclusions were very scanty, but from $60 \mathrm{hr}$. onwards the proportion containing inclusions, and from $120 \mathrm{hr}$. the number of inclusions in each affected trypanosome, increased until the crisis when nearly all circulating trypanosomes contained a large number of inclusions. This 
accumulation is well shown by the figures which demonstrate increase both in the numbers of inclusions and of affected trypanosomes, but the observer gains an even more impressive sense of this accumulation from the striking increase in size and refractility of the individual inclusions. From one to three inclusions occurred in the posterior end of the trypanosome but they were more numerous in the anterior end, often arranged in one or two rows like strings of beads. They were particularly numerous in posterior nuclear forms giving the appearance by their volume (in this strain) of having forced the nucleus over to the posterior end.

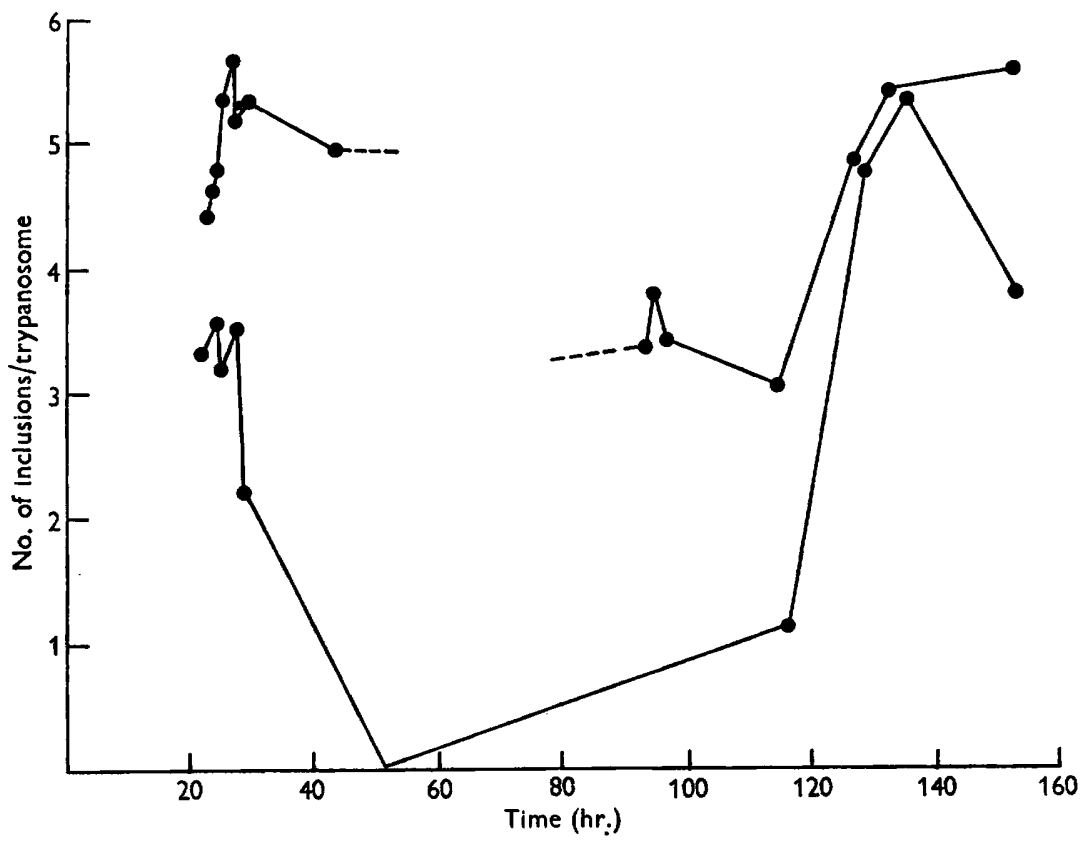

Fig. 3. Trypanosoma rhodesiense. 'Maun' strain. Graph showing the mean number of inclusions/trypanosome based on the infection in six rats. The upper curve was calculated by excluding the trypanosomes which contained no inclusions and shows that in the first $40 \mathrm{hr}$. of infection the individual trypanosomes (presumably derived from the original inoculation) did not lose their inclusions but were themselves eliminated from the circulation. The lower curve, based on the total number of trypanosomes, shows the abrupt fall in inclusion content at the beginning of the infection, rising to a maximum before the crisis. In counting the inclusions an arbitrary maximum of ten inclusions was set for each trypanosome since this seemed to be the greatest number which could be counted with accuracy in the confined space of one organism: the peak figures for inclusion content are lower, therefore, than they should in fact be.

Posterior nucleus forms were very numerous during the few hours preceding the crisis. During the crisis the blood contained numerous refractile globules of the size and appearance of the cytoplasmic inclusions of the stumpy forms.

After the crisis, which never completely cleared the blood, the infection began to increase within 2-3 days. The numbers of long thin and short stumpy forms remained approximately equal and no further crisis was observed. The observations of the infection following the crisis are, however, tentative since 
no exhaustive study was made of this phase of the infection. The rats survived $29 \pm 8.7$ days and death was associated with, and may have been caused by, allergic phenomena, i.e. swelling at the joints and nasal passages. During twelve passages in rats there was no noticeable change in the appearance of the organism or in the survival time of the rats, but the rapid initial development of the infection did not show itself until after three passages in rats.

Strain 2. 'SS 57' strain received from Dr J. R. Baker of E.A.T.R.O., Uganda, had been isolated from man. The infection was contracted on the shore of Lake Victoria between Majanji and Mfangano Island, and the fly was presumed to be Glossina pallidipes. I examined the infection in rats infected from a guinea-pig that had been infected from the patient. The appearance of the trypanosomes (see Pl. 1, fig. 6) was in contrast with those shown by strain 1 . The infection began in the same way with long thin forms quickly changing over to short stumpy ones with gradual rise in the number of inclusions, but inclusions were more numerous, smaller and less refractile than those shown in strain 1.

It was seldom possible to count the inclusions in any one trypanosome or to declare in some instances with certainty whether a trypanosome contained inclusions or not. It was impossible therefore to make counts such as those shown in Figs. 1-3. Generally long thin forms were free from inclusions and short stumpy forms contained numerous inclusions, but exceptions from this rule occurred more frequently in strain 2 than in strain 1: posterior nuclear forms were present late in the infection but were less frequent in this strain, inclusions were equally small in these forms and there was no appearance of the nucleus having been pushed posteriorly. There were no signs of any immune reaction to the very acute infection produced by this strain, no crisis, and no allergic phenomena. The rats survived $9 \pm \mathbf{2} \cdot 8$ days.

Strain 3. 'Vom strain'. This strain was isolated in Bechuanaland 17 months before my observations were made. The history since isolation was as follows:

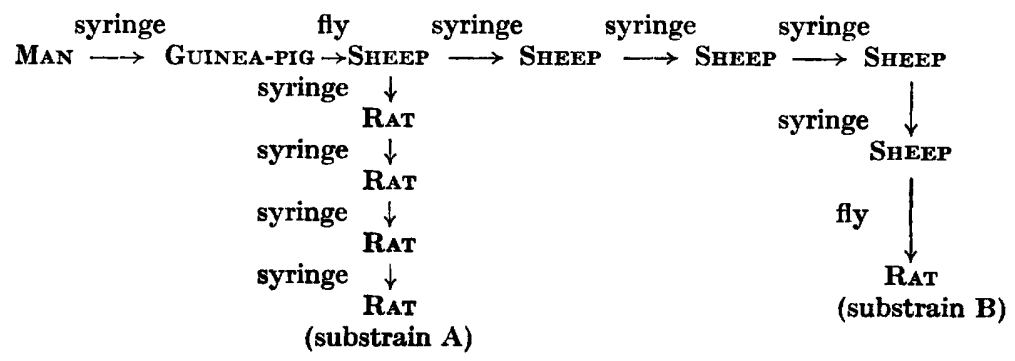

The observations which were made on 2 and 3 February 1955 were as follows:

$S u b s t r a i n, A$ showed a very heavy infection (c. 100 trypanosomes $/ \times 600$ field). The trypanosomes were monomorphic and without inclusions except that c. $1 \%$ of the trypanosomes were of the broad stumpy form with heavy inclusions.

Substrain $B$ showed a heavy infection (c. 20 trypanosomes $/ \times 600$ ); rats infected at the same time showed different rates of infection but identical 
appearances. Long thin forms and short stumpy forms were present in approximately equal numbers and the appearance of granules and their distribution between the types of trypanosomes were identical with those shown in strain 1 as shown in Pl. 1, fig. 5 .

Strain 4. Origin unknown. When first observed it had been maintained by syringe passage in laboratory rats for about 1 month; it was still polymorphic, the limits of which are shown in Pl. 2, fig. 7. One year later the strain was fully monomorphic and without inclusions.

Numerous other strains of Trypanosoma rhodesiense have been examined in various laboratories; all caused acute disease, the rats or mice surviving up to 5 days. The trypanosomes were monomorphic and were without inclusions: the same or similar strains in guinea pigs were more chronic and usually contained inclusions: polymorphism was variable or absent.

(14) Trypanosoma gambiense. I have seen a single trypanosome in the cerebrospinal fluid of a patient with sleeping sickness in the Gambia and three trypanosomes in a mouse infected from a patient from Sierra Leone. Apart from the fact that these four trypanosomes contained multiple inclusions I cannot report on the morphology of inclusions in this species. Strains that I examined adequately had previously undergone multiple syringe passage and had acquired characteristics similar to those acquired by other species of polymorphic trypanosomes treated in this way.

\section{Group V(trypanosomes of cold-blooded vertebrates)}

(15) Trypanosoma rotatorium Meyer, 1843. The leaf-like phase of this trypanosome was observed in two frogs (Rana esculenta) which had been imported from Europe. Only three specimens were seen, one of which is shown in Pl. 3, fig. 8. In each trypanosome rows of inclusions were arranged between the striae; no stained preparations were obtained.

(16) Trypanosoma danilewskyi Laveran \& Mesnil, 1904. Four out of twelve common carp (Cyprinus carpio) from a pond in Essex were found to be infected; the infection was scanty and an adequate study was made only of four individual trypanosomes. Inclusions were present in these large, active, refractile trypanosomes but were often inconspicuous (see Pl. 3, fig. 9; the difference in overall density between the organisms shown in figs. 9 and 10 is not likely to be significant but probably reflects differences in the setting of the phase contrast microscope). A constant feature was a single inclusion or group of inclusions in the region of the kinetoplast.

\section{DISCUSSION}

These inclusions in trypanosomes are usually referred to as 'volutin granules', but it is probably better to call them simply 'inclusions' as this cannot lead one to suppose that their chemical nature is defined. Cytochemical evidence (Van den Berghe, 1942) suggests that they contain ribonucleic acid, but as methods available at present are clearly inadequate for this type of work (see section on Methods), this comparative study has been made solely on the refractility of the inclusions and their superficial appearance. 
In spite of deviations, the overall consistent appearance of these inclusions leads me to suppose that I have been observing a single phenomenon in the different species of trypanosomes in the circulation of warm-blooded animals; the scantiness of evidence in connexion with trypanosomes of cold-blooded animals must exclude them for the present from the discussion.

The phenomenon studied consists of the following features. The appearance of spherical refractile bodies in the cytoplasm which vary in size from the limits of microscopic resolution to $4 \mu$ across and the larger the inclusions, the less refractile appears the rest of the cytoplasm. These refractile bodies have no apparent connexion with the nucleus; in some species, especially of the lewisi group, they form most readily in the region of the kinetoplast, but in the brucei group they are most frequently anterior to the nucleus and are arranged like strings of beads. In some species, such as Trypanosoma lewisi and $T$. cruzi the refractile bodies do not stain with Romanowsky stains, in others ( $T$. nabiasi, $T$. grosi) they stain readily; in $T$. rhodesiense they sometimes stain with ease taking on a deep violet colour, while at other times they show a pale eosinophilia, and at others they do not stain at all. The refractile bodies are not permanent cell structures and appear in the course of development of the trypanosome where they had not been visible before.

In the introduction to this paper I suggested (Ormerod, 1951) that the inclusions might be produced by a substance circulating in the blood of the host, absorbed by the trypanosome and able to disrupt its ribonucleoprotein into constituent protein and ribonucleic acid. No evidence either in proof or disproof of this hypothesis has emerged from the present work, but the results suggest that the phenomenon is in some way connected with an immune reaction on the part of the host and are therefore likely to be of more than theoretical importance in the study of trypanosomiasis. The evidence for this is as follows.

(1) The inclusions do not develop before the 5th day of the infection. (If, however, they are already present in the infecting organisms, they will appear on the first 2 days of the infection but will be absent on the second and third days.)

(2) In Trypanosoma rhodesiense strain 1, the maximum production of inclusions coincided with the crisis; the inclusion-filled trypanosomes were less motile, more fragile and in the last stages of the crisis were apparently moribund.

(3) Trypanosoma rhodesiense strain 1 produced heavy inclusions and was associated with immune phenomena in the host and a long survival time (29 days for rats). Strain 2 produced light inclusions, showed no immune phenomena and had a short survival time (9 days for rats).

(4) Chronic infections are usually associated with the formation of many inclusions; in acute infections the trypanosomes contain few inclusions or none at all. Exceptions to this rule are Trypanosoma avium and the lewisi group where a different mechanism appears to operate.

(5) In Trypanosoma lewisi the appearance of inclusions coincides with the initial check in growth of the organism ascribed by Taliaferro (1941) to a 
growth-inhibiting factor ablastin. The adult forms which contain only one inclusion appear to be insensitive to this factor.

(6) In Toxoplasma gondii inclusions having similar appearance under phase contrast are undoubtedly produced by immune bodies. Analogy with this organism is sufficient to show that an immune reaction with this type of morphology is already known in the phylum Protozoa.

I do not propose to discuss further the possible relationship of inclusions to the immune reaction of the host, but to reserve this topic for a later publication.

A striking relationship, however, exists between polymorphism in trypanosomes and the appearance of inclusions. Inclusions without polymorphism occur in Trypanosoma vivax and $T$. cruzi, so that they do not necessarily go together, but they are closely associated in $T$. rhodesiense (presumably also in $T$. gambiense and $T$. brucei) and in $T$. lewisi and the other flea-transmitted trypanosomes of rodents which resemble it. In these two types of trypanosomes with widely differing life histories and behaviour, multiple inclusions occur only in the broad stumpy and intermediate forms. The long thin forms of $T$. rhodesiense are inclusion-free and those of $T$. lewis $i$ have a single inclusion in the region of the kinetoplast. The broad inclusion-bearing forms in both species are associated in time (if not more directly) with an immune reaction in the host. The appearances suggest that in either case the long thin forms are resistant to this immune reaction; in $T$. lewisi the 'adult' forms are resistant to sera which are lethal to 'developmental' forms (Coventry, 1930), and in $T$. rhodesiense strain 1, the long thin forms divide readily and appear active while the short stumpy forms succumb at the crisis. The difference, however, lies in the reversal of the polymorphism, $T$. lewisi beginning the infection with a form that is susceptible to immune bodies and passing over to one that is resistant, whereas $T$. rhodesiense appears to begin its cycle in the blood with a resistant form passing over to a susceptible.

I wish to acknowledge the receipt of a grant from the Colonial Development and Welfare Fund for technical assistance, and for the expenses of a visit to British West Africa, and from the University of London Central Research Fund for phasecontrast equipment. I should like to thank the Director and staff of the Medical Research Council Laboratories at Fajara, Gambia, and the Director and staff of W.A.I.T.R., Nigeria, for their help and hospitality; also Mr C. B. Hill and Mr R. Killick-Kendrick for technical assistance.

\section{REFERENCES}

Babes, V. (1895). Beobachtungen über die metachromatischen Körperchen, Sporenbildung, Verzweigung, Kolben- und Kapsel-bildung pathogener Bakterien. Z. Hyg. InfektKr. 20, 412.

BAKER, J. R. (1955). Studies on Trypanosoma avium Danilewsky 1885. II. Transmission by Ornithomyia avicularia L. Parasitology, 46, 321.

Barnard, E. A. \& Danielli, J. F. (1956). A cytochemical reaction for nucleoprotein. Nature, Lond. 178, 1450.

Barrow, J. H. (1954). The biology of Trypanosoma diemyctyli. II. Cytology and morphology of T. diemyctyli in the vertebrate host Triturus viridescens. Trans. Amer. micr. Soc. 73, 242. 
BERGHe, L. vaN DEN (1942). Sur la présence d'acide pentosenucléique sous forme des grains de 'volutine' dans les trypanosomes. Acta biol. belg. 2, 464.

Brachet, J. (1941). Localization des acides pentosenucléiques dans les tissus et les œufs d'amphibiens en voie de développement. Arch. Biol., Paris, 53, 207.

Bringmann, G. \& Holz, J. (1953). Licht- und elektronen-mikroskopische Untersuchungen zum Sero-Farbtest auf Toxoplasmose nach Sabin und Feldman. Z. Hyg. InfektKr. 138, 151.

Bruce, D., Harvey, D., Hamerton, A. E., Davey, J. B. \& Bruce, M. E. (1915). Morphology of various strains of the trypanosome-T. brucei vel rhodesiensecausing disease in Nyasaland. Rep. Sleep. Sickn. Comm. roy. Soc. 16, 96.

Casperson, T. \& Brand, K. (1941). Nucleotidumsatz und Wachstum bei Presshefe. Protoplasma, 35, 507.

Coventry, F. A. (1930). The trypanosomal action of specific antiserums on Trypanosoma lewisi in vivo. Amer. J. Hyg. 12, 366.

Dämle, S. P. \& Krishnan, P. S. (1954). Studies on the role of metaphosphate in moulds. I. Quantitative studies on metachromatic effect of metaphosphate. Arch. Biochem. Biophys. 49, 58.

Danielir, J. F. (1947). A study of techniques for the cytochemical demonstration of nucleic acids and some components of proteins. Symp. Soc. exp. Biol. 1, 101.

Desowitz, R. S. \& Watson, H. J. C. (1953). Studies on Trypanosoma vivax. IV. The maintenance of a strain in white rats without sheep serum supplement. Ann. trop. Med. Parasit. 47, 62.

EBeL, J. P. (1952). Recherches sur les polyphosphates contenus dans diverses cellules vivantes. II. Etude chromatographique et potentiométrique des polyphosphates de levure. Bull. Soc. chim. Biol. 34, 330.

ErdmanN, R. (1910). Kern und metachromatische Körper bei Sarkosporidien. Arch. Protistenk. 20, 239.

Garnham, P. C. C. (1956). Isolation of a new strain of Trypanosoma cruzi. Trans. roy. Soc. trop. Med. Hyg. 50, 613.

GERzELI, G. (1955). Richerche istochimiche ed istomorfologiche sui trypanosomidi. Riv. Parassit. 16, 209.

Grimme, A. (1902). Die wichtigsten Methoden der Bakterienfärbung in ihrer Wirkung auf die Membran, den Protoplasten und die Einschlüsse der Bakterienzelle. Zbl. Bakt. 32, 161.

Guilliermond, A. (1910). A propos des corpuscules métachromatiques ou grains de volutine. Arch. Protistenk. 19, 289.

HoARE, C. A. (1957). The classification of trypanosomes of veterinary and medical importance. Vet. Rev. \& Annot. 3, 1.

Hoтchкiss, R. D. (1948). A microchemical reaction resulting in the staining of polysaccharide structures in fixed tissue preparations. Arch. Biochem. 16, 131.

Kossel, A. (1882). Zur Chemie des Zellkerns. Hoppe-Seyl. Z. 7, 7.

Kunze, W. (1907). Über Orcheobius herpobdellae Schuberg et Kunze. Arch. Protistenk. 9, 382.

Lelong, M. \& Desmonts, G. (1951). L'emploi du microscope à contraste de phase dans la réaction de Sabin-Feldman. C.R. Soc. Biol., Paris, 145, 1660.

Lison, L. (1935). Études sur la métachromasie, colorants métachromatiques et substances chromotropes. Arch. Biol., Paris, 46, 599.

Meyer, A. (1904). Orientierende Untersuchungen über Verbreitung, Morphologie und Chemie des Volutins. Bot. Ztg, 62, 113.

Mrchaelis, L. (1944). Theory of metachromatic staining. Biol. Bull., Wood's Hole, $87,155$.

Minchin, E. A. (1909). The structure of Trypanosoma lewisi in relation to microscopical technique. Quart. J. micr. Sci. 53, 755. 
MrTchell, J. S. (1942). Disturbance of nucleic acid metabolism produced by therapeutic doses of $\mathbf{X}$ and gamma radiations. II. Accumulations of pentose nucleotides in cytoplasm after irradiation. Brit. J. exp. Path. 23, 296.

Nigrelu, R. F. (1929). On the cytology and life history of Trypanosoma diemyctyli and the polynuclear count of infected newts (Triturus viridescens). Trans. Amer. micr. Soc. 48, 366.

Ormerod, W. E. (1951). A study of basophilic inclusion bodies produced by chemotherapeutic agents in trypanosomes. Brit. J. Pharmacol. 6, 334.

Rego, S. \& Garnham, P. C. C. (1956). The ' $Y$ ' strain of Trypanosoma cruzi: leishmanial development in the spleen of mice. Trans. roy. Soc. trop. Med. Hyg. 50, 299.

Reichenow, E. (1910). Haemogregarina stepanovi. Die Entwicklungsgeschichte einer Hämogregarine. Arch. Protistenk. 20, 251.

Sabin, A. B. \& Feldman, H. A. (1948). Dyes as microchemical indicators of a new immunity phenomenon affecting a protozoon parasite (Toxoplasma). Science, 108,660 .

Salvin-Moone, J. E. \& Breinl, A. (1908). The cytology of Trypanosomes. I. Ann. trop. Med. Parasit. 1, 441.

Swellengrebel, N. H. (1908). La volutine chez les trypanosomes. C.R. Soc. Biol., Paris, 64, 38.

Taliaferro, W. H. (1941). The immunology of the parasitic protozoa. In Protozoa in Biological Research, p. 830. Eds. Calkins, G. N. \& Summers, F. M. New York: Columbia University Press.

Thompson, J. G. \& de Muro, P. (1932). The influence of Treponema duttoni on an infection with Trypanosoma rhodesiense in mice. J. trop. Med. Hyg. 35, 33.

WaLton, K. W. (1952). The biological behaviour of a new synthetic anticoagulant (dextran sulphate) possessing heparin-like properties. Brit. J. Pharmacol. 7, 370.

Wenyon, C. M. (1926). Protozoology., London: Baillière, Tindall and Cox.

Wiame, J. H. (1947). Étude d'une substance polyphosphorée, basophile et métachromatique chez les levures. Biochim. biophys. Acta, 1, 234.

Wolcotт, G. B. (1952). Mitosis in Trypanosoma lervisi. J. Morph. 90, 189.

\section{EXPLANATION OF PLATES}

\section{Plate 1}

Fig. 1. Trypanosoma lewisi. 45th day of infection; freehand drawing of trypanosomes on agar as seen by phase-contrast. The adult forms show one (or less frequently two) inclusions posterior to the region of the kinetoplast.

Fig. 2. Trypanosoma lewisi. 7th day of infection, broad forms showing multiple inclusions in the region of the kinetoplast.

Fig. 3. Trypanosoma grosi. Inclusions appear either in the region of the kinetoplast or between the nucleus and the kinetoplast.

Fig. 4. Trypanosoma cruzi. The body of the trypanosome is crammed with inclusions; the position of the nucleus is shown by the area without inclusions.

\section{Plate 2}

Fig. 5. Trypanosoma rhodesiense. 'Maun' strain. This strain, which produces a marked immune reaction in rats, shows large and very distinct inclusions, which are present only in broad and intermediate forms.

Fig. 6. Trypanosoma rhodesiense. Strain SS57. Inclusions are smaller and less easily distinguished than in the Maun strain, usually confined to broad and intermediate forms. Little immune reaction was produced in rats. 
Fig. 7. Trypanosoma rhodesiense. Strain of unknown origin. Extreme forms: posterior nuclear form, very slow-moving and filled with inclusions. (The inclusions present in the undulating membrane are probably a unique feature of this individual organism): long thin form without inclusions. (The blunt posterior end was seen frequently in this strain.)

\section{Plate 8}

Fig. 8. Trypanosoma rotatorium. Inclusions are arranged in rows between what appear to be muscular striations.

Figs. 9, 10. Trypanosoma danilezeskyi.

(Received 13 March 1958) 
Journal of General Microbiology, Vol. 19, No. 2
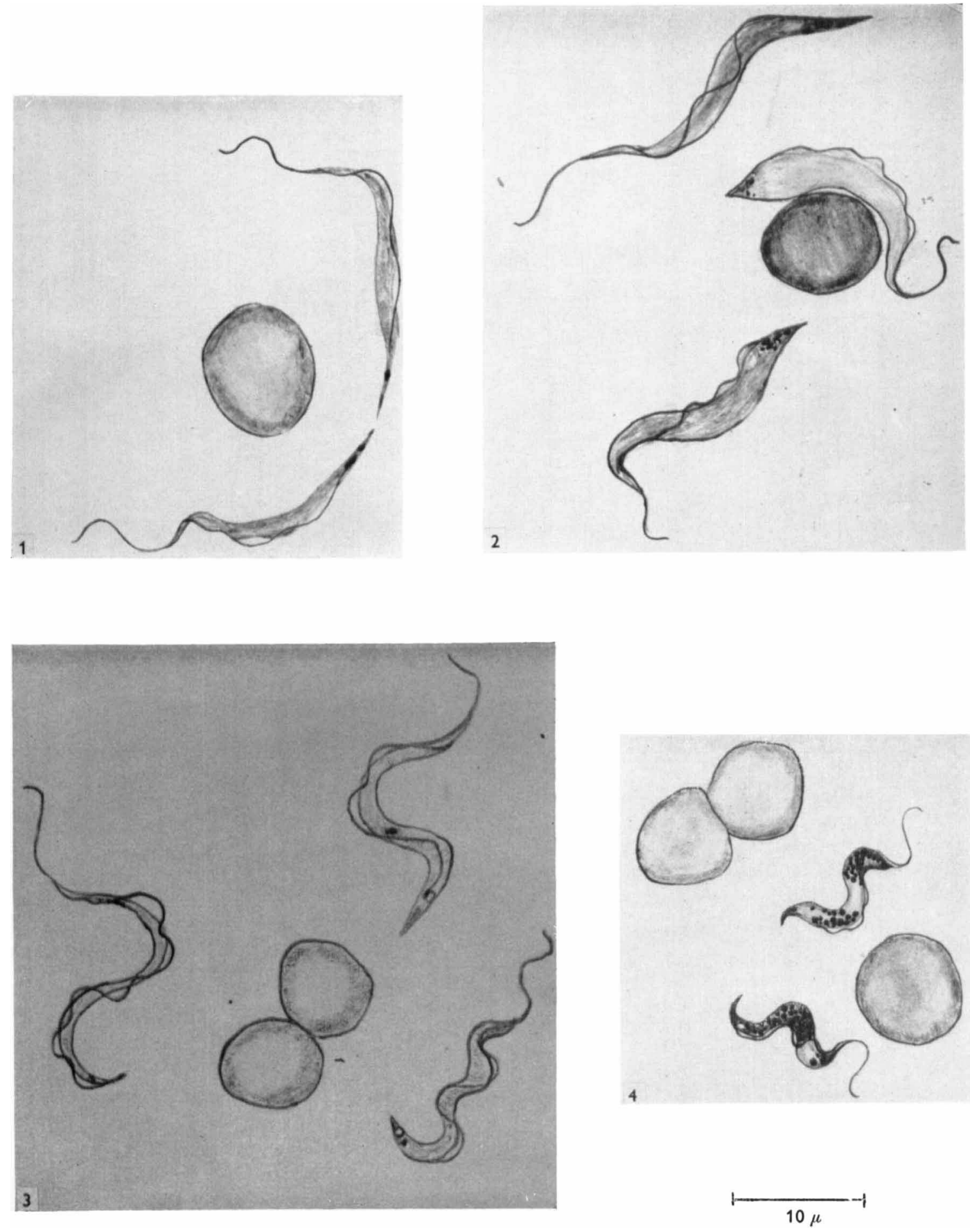

W. E. Ormerod-Volutin granules in trypanosomes. Plate 1. 
Journal of General Microbiology, Vol. 19, No. 2
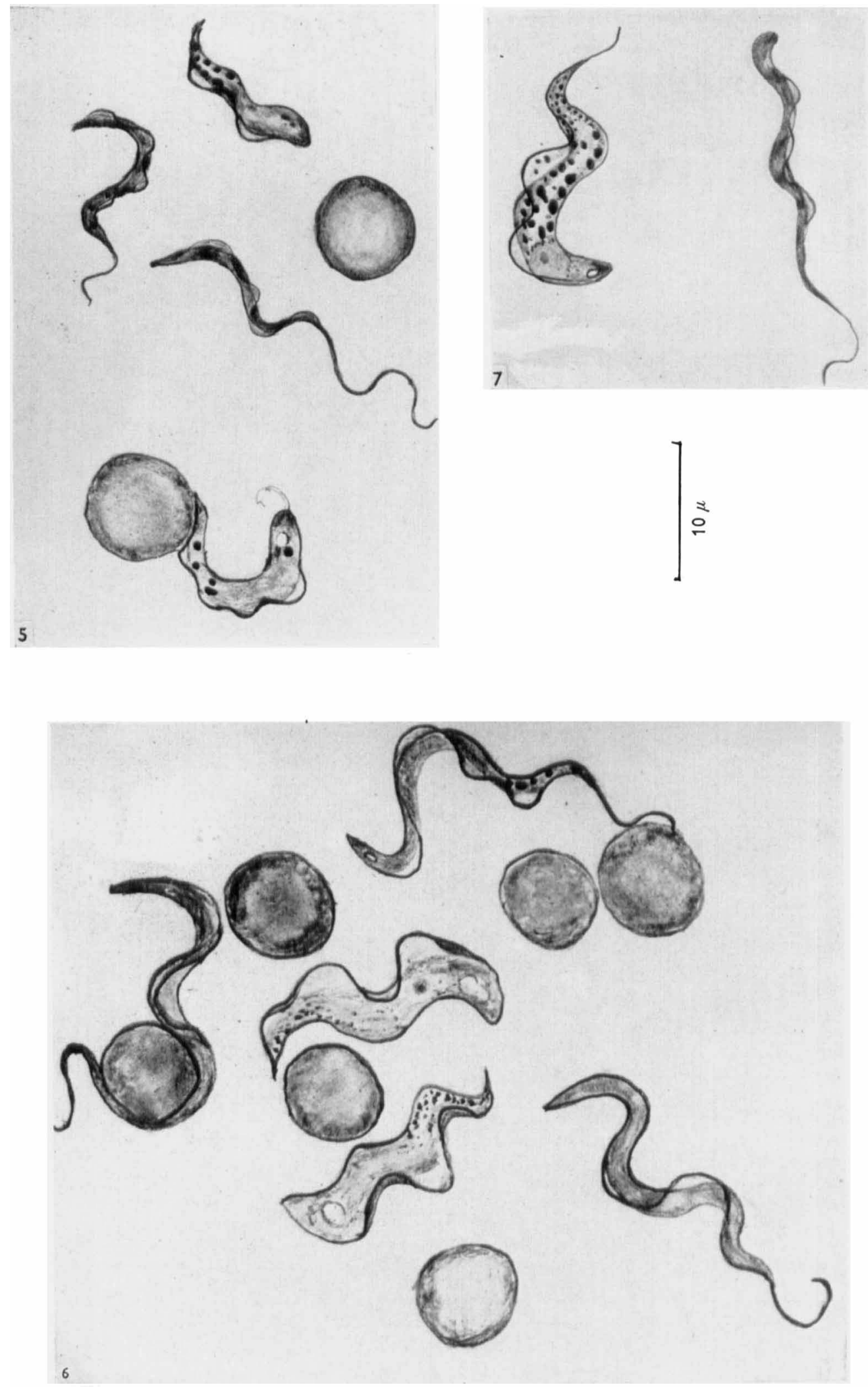

W. E. Ormerod--Volutin granules in trypanosomes. Plate 2 
Journal of General Microbiology, Vol. 19, No. 2
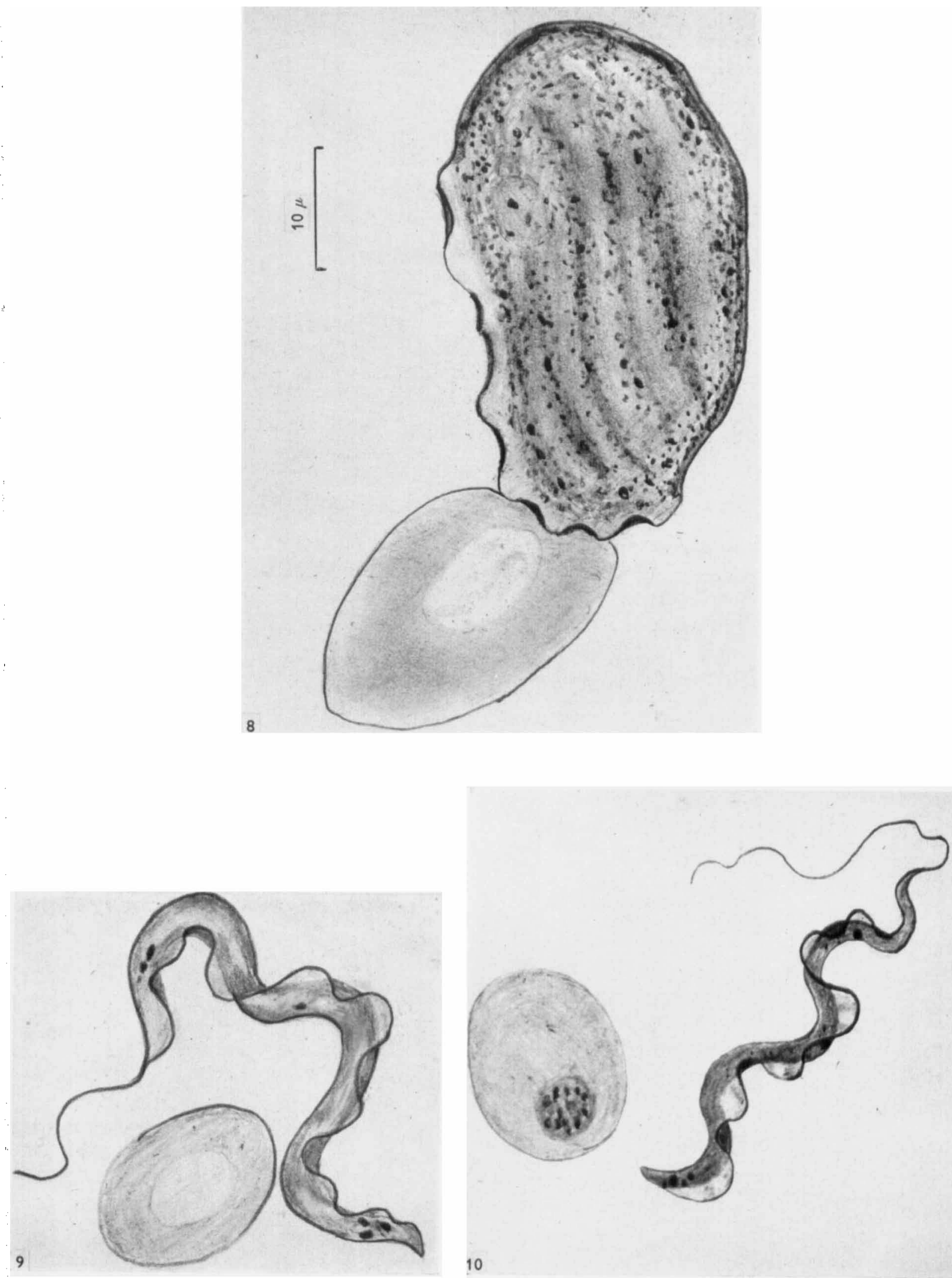

W. E. Ormerod-Volutin granules in trypanosomes. Plate 3 